\title{
Carcinogen Resistance
}

National Cancer Institute

\section{Source}

National Cancer Institute. Carcinogen Resistance. NCI Thesaurus. Code C19392.

The natural or acquired ability of an org anism to maintain its immunity to or to resist the effects of a cancer causing agent. 